\title{
"A lei ficou louca"; A Lei Maria da Penha e os efeitos da incondicionalidade da lesão corporal no trabalho policial em duas DDM de São Paulo' ${ }^{1}$
}

\author{
BeATriz ACCIOLY Lins \\ Universidade de Sáo Paulo, São Paulo, São Paulo, Brasil
}

DOI: $10.11606 /$ issn.2316-9133.v22i22p289-300

resumo Em 2006, foi promulgada a Lei no 11.340 , Lei Maria da Penha, com o propósito de criar mecanismos para coibir a violência doméstica e familiar contra a mulher. Viso compreender de que maneira tal mudança teria impactado a prática e falas policiais em de duas Delegacias de Defesa da Mulher da cidade de São Paulo, investigando a interação das policiais com a nova lei e as mudanças nela previstas, os significados que lhe são atribuídos, e mais especificamente os efeitos da decisão do Supremo Tribunal Federal, de fevereiro de 2012, de transformar o delito de lesão corporal, dentro do contexto da violência doméstica, em ação pública incondicionada, isto é, retirando da mulher a decisão de transformar o registro da ocorrência em investigaçấo e instaurando o inquérito policial a despeito da vontade da vítima.

palavras-chave Lei Maria da Penha; Delegacia de Defesa da Mulher; Violência doméstica; Polícia

"The law went crazy": Maria da Penha law and the effects of the "incondicionalidade' of bodily harm crimes in police work in two Women's Police Stations in São Paulo

abstract In 2006, law No. 11.340, also known as Maria da Penha Law, was enacted in Brazil, with the purpose of creating mechanisms to prevent domestic and family violence against women. In my research, I seek to understand how such a change would have impacted the practice and discourse of police officers in two Women's Police Stations in São Paulo, investigating the interaction of the police officers with the new law and the changes it brings, the meanings attributed to it, and more specifically the effects of the decision of the Supreme Court, in February 2012, to transform the offense of bodily harm, within the context of domestic violence, criminal investigation despite the wishes of the victim. keywords Maria da Penha Law; Women's Police Stations; Domestic violence; Police

The decisions of street-level bureaucrats, the routines they establish, and the devices they invent to cope with uncertainties and work pressures, effectively become the public policies they carry out.

Michael Lipsky, Street Level Bureaucracy

Diariamente, diversas mulheres dirigem-se à uma das nove Delegacias de Defesa da Mulher (DDM) em atividade na cidade de São Paulo visando registrar denúncias ou buscar orientaçôes sobre situaçóes de violência doméstica e familiar que vivenciam ou testemunham. Em uma quantidade significativa das vezes, os casos levados às DDM são agressóes físicas que deixam marcas evidentes não só nos relatos e sentimentos expostos, mas nos corpos que transitam pelos corredores e espaços das delegacias. Entre falas, choro e perguntas, é comum que os balcôes de atendimento das delegacias reúnam 
mulheres que trazem em si os indícios de relaçóes afetivas e familiares turbulentas e agressivas na forma de hematomas, arranhóes e machucados. Desde agosto de 2012, conduzo uma pesquisa etnográfica em duas Delegacias de Defesa da Mulher da cidade - localizadas no centro e no extremo sul periférico de São Paulo. ${ }^{2}$ Em ambas as delegacias, os casos de agressóes físicas que deixam marcas nos corpos são, invariavelmente, tratados como denúncias de lesâo corporal (art. 129 do Código Penal) e registrados em ocorrências que, desde fevereiro do mesmo ano, se configuram como açóes incondicionadas, isto é, transformam-se imediatamente em inquéritos policiais, investigaçóes preliminares enviadas para a instância judicial responsável pelos casos: os Juizados de Violência Doméstica e Familiar contra a Mulher (JVD).

Este artigo tem como foco a busca por uma compreensão mais aprofundada das nuances e dos significados do trabalho policial no cotidiano dessas duas Delegacias de Defesa da Mulher a partir das mudanças trazidas pela Lei Maria da Penha, com atenção especial para os efeitos da uniformização da incondicionalidade da lesão corporal. Em minha experiência de campo, o fato de a denúncia ter passado a se transformar em investigação e processo criminal a despeito da vontade da vítima trouxe efeitos significativos para o trabalho nas delegacias, gerando um aumento substancial na quantidade de inquéritos e criando diferentes estratégias policiais para o tratamento dos casos atendidos.

\section{Separando o joio do trigo: a qualificaçáo dos casos de violência doméstica e os efeitos jurídico-penais de seus encaminhamentos}

Para entender o efeito da recente alteração de tratamento dos casos de lesão corporal, é preciso saber que não são todos os Boletins de Ocorrência $(B O s)$ registrados em uma DDM que se transformam em inquéritos policiais. A princípio, um $B O$ é apenas um registro - nem sempre criminal - realizado na instância policial, que pode ou não ter consequências jurídicas para os envolvidos. São as policiais que decidem, analisando os relatos das pessoas que buscam a delegacia, quais narrativas poderiam ser classificadas como crimes, e em quais tipos criminais cada caso relatado será registrado. Em se tratando de relatos passíveis de serem qualificados em tipos criminais, as ocorrências mais comuns nas DDM costumam ser divididas, pelas policiais, em duas categorias: os casos de violência doméstica, registrados na lei 11.340/06 (Lei Maria da Penha) e casos de estupros, que podem ser registrados como simples ou de vulnerável. ${ }^{4}$

Nos casos enquadrados na categoria de violência doméstica, as ocorrências registradas nas DDM geralmente observam três tipos criminais principais: a lesão corporal (art. 129 do Código Penal), a ameaça (art. 147) e a injúria (art.140). Para além da nomenclatura, o enquadramento dos relatos das vítimas em cada uma dessas naturezas determina o tratamento jurídico-policial posterior desses $B O s$ tanto na polícia quanto nos juizados, e as diferenças entre os possíveis destinos das denúncias, embora possam escapar às vítimas, são extremamente relevantes para as saídas jurídicas - e puniçóes - posteriores.

Neste momento, é preciso aventurar-se por mais uma tecnicidade jurídica. Em se tratando da Lei Maria da Penha, atualmente, as ocorrências de lesão corporā são "açôes públicas incondicionadas", o que significa que uma vez feita a denúncia, esta se transforma em investigação policial e será encaminhada à justiça independentemente da vontade da vítima. A ameaça, por sua vez, é uma "ação pública condicionada”, e para se transformar em uma investigação policial e em processo criminal, depende que a 
vítima expresse intenção de processar o acusado, comunicando à polícia sua decisão de fazer uma representação daquela queixa. O prazo para representar uma ameaça é de seis meses a partir da data dos fatos registrados. Embora as policiais se esforcem para esclarecer as vitimas a respeito dessa significativa diferença entre ameaças e agressóes, nem sempre parece ficar clara a importância desta distinção para o tratamento jurídico-policial das ocorrências registradas. Nesse sentido, o procedimento da representação parece ser bastante confuso para as mulheres que buscam as DDM. Em diversos momentos, tive a impressáo de que algumas deixavam o plantão carregando diversos papéis e algumas orientaçóes, mas sem a clareza das consequências de suas escolhas.

Se é comumente difícil que as vítimas entendam as nuances e tecnicidades do linguajar jurídico para distinguir lesóes de ameaças, nos casos de injúria a incompreensão parece ser ainda mais generalizada. Injúria é o tipo criminal no qual são geralmente enquadrados casos de ofensas, xingamentos e agressões verbais relatados pelas vitimas. Destaca-se que o que é considerado ofensivo pode variar profundamente de acordo com cada profissional. Em geral, privilegiam-se como injúrias termos que agridam a moral sexual da mulher, como "vagabunda", "vadia" ou "puta". Diferentemente da lesão corporal e da ameaça, a injúria é uma "ação privada”, e necessita que a vítima, para além de realizar o registro policial, procure pelos serviços de um advogado e, também, entre com uma queixa-crime no fórum criminal, para, só assim, transformar a ocorrência em um processo contra o acusado. As policiais enfatizam para as mulheres essa hierarquização no caso das ofensas, esclarecendo que, juridicamente, xingamentos seriam inferiores a agressóes.

No período em que tive acesso aos processos criminais das delegacias, isto é, a partir de
2012, nos cartórios das DDM acompanhadas, os inquéritos são majoritariamente oriundos de ocorrências de lesão corporal, devido, sobretudo, à incondicionalidade do crime, embora também se encontre algumas representaçóes de ameaças. São poucos os casos de investigação em se tratando de injúrias.

\section{"Agora é lei": antes e depois da Lei Maria da Penha e os efeitos de fevereiro de 2012}

Em sete de agosto de 2006 foi promulgada pelo governo federal a Lei no $11.340 / 2006$, conhecida como Lei Maria da Penha, responsável pela definição da primeira norma jurídica visando à punição e à prevenção à violência doméstica e familiar ${ }^{6}$ contra mulheres no Brasil. Promulgada no mês anterior, a lei surgiu tanto como uma resposta tardia a articulações de diferentes demandas de organizaçóes de defesa dos direitos das mulheres que reivindicavam medidas mais austeras contra os autores de violência contra as mulheres, assim como uma tentativa do Estado brasileiro de se adequar à diversas convenções internacionais dos quais é signatário, ${ }^{7}$ ampliando o acesso à justiça para suas cidadãs.

O texto da nova lei tipifica como crimes hediondos delitos que, até então, encontravam-se em uma alçada de legislaçôes genéricas consideradas mais vulneráveis às reproduções das desigualdades de gênero; e pune de maneira rigorosa conflitos que costumavam ser trivializados e tratados condescendentemente pelo sistema de justiça brasileiro. A partir de 2006, o Agora é lei se transformou em um importante jargão daqueles que lutaram pelo aumento do rigor punitivo para autores das agressóes contra mulheres, pelo menos em âmbito doméstico e familiar.

No entanto, apesar do tom majoritariamente positivo, parecia ser também generaliza- 
da cautela que chamava atençáo para o fato de que, para além das inovaçóes normativas que a Lei Maria da Penha anuncia, seriam necessárias altas dose de atenção, vigilância e paciência até que a nova lei fosse absorvida e efetivamente aplicada em casos reais levados à justiça. Após a vitória, restou a dúvida: seria a lei aplicada de fato ou as diferentes esferas da justiça responsáveis pelo seu tratamento encontrariam formas de subutilização ou até mesmo de boicote ao que está estipulado em seu texto?

Visando sanar tal limitação, entendeu-se ser vital mobilizar esforços para investigar a inserção da Lei Maria da Penha dentro das instâncias responsáveis pela sua aplicação, em especial as Delegacias de Defesa da Mulher e os recém-criados Juizados de Violência Doméstica e Familiar contra a mulher (JVD). Dentro deste contexto, buscando sinalizar possíveis incongruências entre a lei enquanto norma e a lei enquanto prática, pesquisadoras teceram importantes críticas e ressalvas quanto à efetiva aplicaçáo da lei, isto é, sua existência de acordo com a normativa estabelecida a partir das interpretaçóes conferidas por profissionais do sistema de justiça. ${ }^{8}$

Tais análises, em geral, apontam para os obstáculos e entraves que a lei teria passado a enfrentar dentro do próprio sistema de justiça, começando com a atuação da polícia nas delegacias, passando pelos demais órgãos da rede de atendimento e culminando na atividade de promotores, defensores e juízes dentro dos juizados especializados. Grosso modo, observou-se que antigas ressalvas feitas ao trabalho de profissionais que lidavam com mulheres em situação de violência doméstica continuavam pertinentes, tais como o descaso e a desconfiança para com os relatos das vítimas e a permanência de práticas que influenciavam negativamente a aplicação da lei, gerando possibilidades de burlar a norma e assim, auxiliando a perpetuar a violência.
De maneira fortuita, minha pesquisa de campo teve início durante um período de transição para as duas DDM acompanhadas. Tal mudança foi oriunda de diversas críticas feitas a obstáculos e entraves que a Lei Maria da Penha continuava a encontrar entre os operadores do direito, uma vez que, sendo necessária a vontade da vítima para que os casos registrados nas delegacias se transformassem em investigaçóes, na maior parte das vezes os $\mathrm{BO}$ s não seguiam adiante e não traziam consequências para os acusados ou para as vitimas.

Visando responder a esta limitação, em fevereiro de 2012, o Supremo Tribunal Federal (STF) brasileiro decidiu tratar, uniformemente, os casos de lesáo corporal - registrados dentro do contexto da violência doméstica - como "ações públicas incondicionadas". Anteriormente à decisão do Supremo, não havia consenso sobre a necessidade de representação nos casos de lesão corporal, dependendo do juiz da vara a decisão acerca do seguimento do processo (ZAPATER \& PERRONE, 2010). Apesar de, à primeira vista, a tecnicidade do linguajar jurídico não deixar evidente, tal decisão representou uma significativa mudança no tratamento de alguns casos de violência doméstica que chegam à esfera jurídico-policial.

Nas duas DDM, em que realizo minha pesquisa, a alteração foi sentida de maneira drástica. Antes de fevereiro, de maneira geral, optava-se por instaurar inquéritos de lesão corporal somente se as vitimas expressassem intenção de processar os acusados ou se as delegadas entendessem a necessidade de uma investigação do ocorrido. Nos demais casos, o trabalho policial se limitava ao registro da ocorrência. Nesse sentido, a decisão do Supremo teve efeitos quantitativos relevantes no volume de trabalho destas DDM, em especial no aumento expressivo do número de inquéritos instaurados, fazendo com que as policiais destas delegacias considerem esta mu- 
dança mais significativa do que a própria promulgação da Lei Maria da Penha.

Se a promulgação da Lei Maria da Penha foi interpretada por alguns grupos militantes como uma mudança positiva no tratamento da violência doméstica em âmbito jurídico-policial, no dia a dia do trabalho policial das DDM, as poucas policiais que viveram a transição nas DDM acompanhadas - devido à alta rotatividade de alocaçóes na Polícia Civil de Sáo Paulo -, perceberam a alteração como apenas um ajuste nos procedimentos burocráticos realizados na delegacia. Uma das delegadas me explica que a Lei Maria da Penha não mudou o dia a dia do nosso trabalho, foi só uma adaptação. Só que, quando veio a mudança para incondicionada, quase tudo que registramos vira inquérito, a gente não dá conta. Sua colega escrivã concorda e acrescenta: Ainda por cima temos que lidar com as mulheres que pedem para retirar a queixa, que fazem escândalo. Isso só piorou o trabalho.

No entanto, a partir de 2012, como ressaltou uma escrivã, a lei ficou louca, o volume de trabalho aumentou consideravelmente, sobrecarregando, em especial, as escrivãs de cartório, responsáveis pela condução dos inquéritos, a emissão de intimaçôes e depoimentos de vítimas, autores e testemunhas. Do ponto de vista numérico, por exemplo, em uma das DDM acompanhadas, o número de inquéritos instaurados passou de 554, em 2011, para 1126, em 2012. Na outra DDM em que conduzo minha pesquisa, o número passou de 366, em 2011, para ostensivos 1780 em apenas doze meses.

No dia a dia das DDM, percebe-se que a incondicionalidade da lesão corporal também afetou consideravelmente a postura das mulheres diante da decisão de transformar agressóes em ocorrências. Acompanhei diversos casos de mulheres que optaram por não registrar a queixa uma vez que tomavam conhecimento de que a denúncia se transformaria automaticamente em investigação/processo e que seria necessária uma audiência com um juiz para resolver o caso. Muitas dessas mulheres se mostravam frustradas e insatisfeitas com a mudança na lei. Também foram recorrentes as situaçôes em que mulheres compareciam às delegacias buscando retirar as queixas, e ao serem informadas da impossibilidade entravam em conflito com as policiais. ${ }^{10}$ Como explica uma delegada: a decisáo do STJ é complicada, pois a mulher perdoa, volta para o cara e o inquérito fica correndo, o que gera uma nova crise na relação conjugal.

$\mathrm{Na}$ tentativa de dar conta do repentino aumento de processos em seus cartórios, as policiais encontram saídas e interpretaçóes distintas para lidar com os dilemas trazidos pela incondicionalidade. Há divergências significativas, por exemplo, por parte das policiais, a respeito da possibilidade de informar ou não as vítimas $\mathrm{da}$ especificidade dos casos de lesão corporal. Para uma parte das profissionais com as quais convivo, deve ser dada às mulheres a opção de não registrar a ocorrência, uma vez que não há mais como retirar a queixa, e se a mulher desistir do processo, o inquérito continuará existindo, criando um problema para vitima e para as profissionais. Outras policiais defendem, de forma oposta, que não se informe as vítimas a respeito do caráter incondicional dos casos de lesão corporal, justamente para que não haja a possibilidade de não realizaçáo do registro.

As policiais do primeiro grupo geralmente avisam inicialmente as mulheres que agressáo vira processo e costumam enfatizar a necessidade de ter certeza sobre o desejo de processar o acusado no momento da denúncia. Você não pode mais voltar atrás, aconselha uma das investigadoras responsável pelo pré-atendimento. Estas profissionais argumentam que haveria uma quantidade relevante de inquéritos nos quais as mulheres não mais buscam a punição judicial do autor, mas que, devido à decisão do Supremo, continuam a existir e a exigir pro- 
vidências policiais, criando problemas para as funcionárias das delegacias. Nesses casos, na percepção das policiais, seriam as vítimas - e não a polícia - que encontrariam maneiras de burlar a normativa estabelecida na lei, ao não realizarem procedimentos obrigatórios para a condução dos inquéritos, como o exame de corpo-delito e depoimentos, ou até mesmo escondendo de seus companheiros as intimaçôes policiais e evitando a colheita de oitivas.

Por outro lado, mesmo que discordem da incondicionalidade, há policiais que defendem a não prerrogativa das vítimas de registrar ou não casos de agressáo física. Para estas profissionais, avisar as mulheres acerca da transformação da ocorrência em processo corresponderia a desencorajá-la a buscar auxílio na justiça. Nesse sentido, as vítimas não teriam a prerrogativa de utilizar ou não a lei, uma vez que já procuraram os serviços da polícia. Como explica uma delegada: eu entendo a questão da incondicionalidade na medida em que as mulheres têm medo e não têm força para sair desse ciclo de violência. Nós não podemos dar a opção, ela náo vai querer se defender. Se nós vemos uma mulher chegar machucada e não registramos, somos nós que a estamos violentando novamente. É negligência.

A despeito de divergências de práticas e opiniōes, de modo geral, a mudança no tratamento dos casos de lesão corporal gerou insatisfação em quase todas as funcionárias das duas DDM em que acompanho o expediente. Para as policiais, a incondicionalidade teria aumentado desumanamente a carga de trabalho nas delegacias, impossibilitando que os inquéritos sejam conduzidos em uma velocidade considerada razoável, sobrecarregando o trabalho das escrivãs, diminuindo a qualidade das oitivas ${ }^{11}$ e tirando a possibilidade da vítima de negociar com o autor da violência através da prerrogativa da representação. Como explicou uma escrivã: antes a mulher fazia o $B O$, tinha seis meses para representar e ficava falando para o homem: se me bater de novo, eu vou lá e processo. As mulheres tinham esse papel, o BO, que dava um poder de peitar o cara. Agora acabou.

As percepçóes das policiais a respeito das expectativas das vítimas são confirmadas em algumas experiências na delegacia. Para uma boa parte das mulheres que buscam as DDM, a incondicionalidade da lesão corporal também trouxe frustraçôes de diferentes naturezas. Uma parcela significativa das mulheres se reconcilia com companheiros, namorados, maridos ou outros familiares após terem realizado o registro da ocorrência e reclama do fato do processo continuar existindo a despeito de sua vontade. Estou morando com ele, e ontem chegou uma intimação, ai que ele ficou bravo mesmo e vai me bater de novo, reclamou uma das vitimas à escrivã.

Há casos também em que a vítima, ao prestar depoimento na delegacia no momento da oitiva, reitera seu desejo de não dar prosseguimento ao processo, uma vez que o motivo da queixa não mais existiria, seja porque o autor deixou de agredi-la ou porque teria havido uma separação ou afastamento. Para essas mulheres, a persistência do processo policial também significa um importante constrangimento em uma situação em que a violência deixara de ocorrer. Nesses casos, cessa-se a violência, mas não os procedimentos burocrático-policiais, gerando transtornos emocionais e práticos.

No entanto, a insatisfação mais comum por parte das mulheres que procuram as DDM para registrar casos de violência doméstica em relação a não possibilidade de "retirar a queixa" em casos de lesão corporal se expressa no medo de que o denunciado passe a ter a ficha suja, ${ }^{13}$ isto é, antecedentes criminais que o impeçam, sobretudo, de conseguir postos de trabalho. As policiais favoráveis à escolha da vitima quanto ao registro da ocorrência costumam enfatizar esse elemento em suas orientaçóes às mulheres. Ele vai ter fi- 
“A LEI FICOU LOUCA"| 295

cha criminal, não vai conseguir emprego. Você depende dele financeiramente? Vai precisar de pensão?, costuma perguntar uma das escrivâs. Outra forma de tentar baixar o acervo de inquéritos da delegacia, encontrada pelas policiais, seria desencorajar que mulheres que tenham registrado ameaças decidam representar e transformar aquele $\mathrm{BO}$ em inquérito. Nesses casos, percebe-se a preocupação com o volume de trabalho nos cartórios e a possibilidade de que este inquérito se torne um problema administrativo.

Dentro das DDM, sobretudo para as escrivãs (responsáveis por tocar os inquéritos policiais), o sucesso e a resolução de um caso são medidos pelo relato do inquérito, isto é, sua conclusão na fase policial. Se aquela determinada investigação obedeceu todos os procedimentos obrigatórios (em geral, o laudo e oitivas de vitimas, autores e testemunhas) em prazo ideal para que fosse concluída, ela fica somente o tempo ideal na delegacia, logo seguindo para a instância judiciária responsável por sua resoluçáo. Por outro lado, quando um inquérito não segue adiante, as policiais apontam impedimentos impostos pela vitima - como a náo realização do exame no Instituto Médico Legal ou a impossibilidade de encontrar e ouvir em depoimento as partes envolvidas - como entraves à boa condução e ao sucesso de seu trabalho. Assim, inquéritos relatados e enviados à justiça parecem ser a medida da eficiência do trabalho dentro das delegacias. Em outras palavras, no trabalho com a violência doméstica, as policiais indicam considerar seu trabalho eficaz e bem realizado na medida em que concluem burocraticamente as investigaçóes. Nesse sentido, as demandas e experiências relatadas pelas vítimas são substituídas pelo cumprimento de normas e procedimentos burocrático-policiais na avaliação da eficiência do trabalho policial.

\section{Lei é lei, minha filba, ele náo pode te bater $^{13}$ : a lei é dura, mas é a lei?}

Dentro das delegacias, a relação das policiais com a lei não é despida de contradiçóes e ambiguidades. Para muitas policiais, a norma jurídica não seria necessariamente legítima e elas admitem que algumas leis - em especial a Lei Maria da Penha - contradiriam alguns de seus valores pessoais. Não concordo, mas tenho que aplicar, é uma fala comum a algumas funcionárias das delegacias acompanhadas. Uma delegada explicou mais detidamente: $E$ u faço o $B O$ de Lei Maria da Penha sempre. Às vezes não é o meu entendimento jurídico, a minha verdade jurídica, mas, para evitar problemas, eu sempre faço.

Percebe-se que, nessa perspectiva, embora juridicamente sinalizada como crime, a violência doméstica contra mulheres, em muitas situações, não é vista como moralmente condenável para estas profissionais. Muitas falas e práticas são demasiadamente ambíguas quando se trata da condenação ou não de práticas violentas em relaçôes íntimas e familiares, e oscilam de acordo com determinadas circunstâncias. Ao mesmo tempo, mesmo com discordâncias, as policiais reconhecem serem compelidas a cumprir as normas estipuladas. Nesse sentido, embora as leis sejam criticadas como manipuláveis, burláveis e por vezes em desacordo com crenças pessoais, elas também teriam um caráter inviolável, superior e incontestável. Assim, o discurso direcionado a outras funcionárias, ao público e a mim, também poderia adquirir a forma da defesa da aplicação efetiva da lei a despeito das opinióes pessoais. Lei é lei, não tem essa de aplicar ou não, me contou um investigador. Eu, às vezes, acho que a mulher está exagerando, que ela quer mais é se vingar do cara, mas pelo sim ou pelo não, a vítima tem sempre razão e eu faço o $B O$, reiterou uma delegada.

A força superior e inquestionável da lei é constantemente enfatizada em falas que privi- 
legiam o caráter de lei da Lei Maria da Penha, isto é, sua aplicação a despeito dos comportamentos e valores de cada pessoa. Com a lei Maria da Penha não é mais a casa da mãe Joa$n a$, costuma afirmar um investigador. Não pode mais bater na sua mulher, os tempos mudaram, também avisa uma escrivã aos autores.

No dia a dia das DDM testemunhei a utilização da Lei Maria da Penha no registro de casos que poderiam, à primeira vista, fugir de uma definição pautada em papéis de gênero mais tradicionais (como marido e esposa ou pai e filha). Apesar da maior parte das ocorrências serem entre companheiros ou cônjuges, nos plantóes são registradas como ocorrências de violência doméstica casos de agressóes, ameaças e ofensas em relaçóes homo afetivas entre mulheres, namorados, pessoas que haviam se envolvido sem constituir uma relação amorosa, familiares (cunhados, sogras, sogros, tios) e vizinhos. Eu uso Lei Maria da Penha para tudo por ela ser mais rigorosa, senáo vai para a cesta básica. Se eu puder cavar uma Maria da Penha, eu cavo, afirma uma das delegadas.

Nesse sentido, a Lei Maria da Penha é compreendida como uma ferramenta positiva para conseguir puniçóes mais contundentes. As policiais costumam indicar como elementos positivos justamente a possibilidade da prisão em flagrante e a existência de medidas protetivas de urgência que visam afastar vítima e autor, ${ }^{14}$ ambas entendidas como sinalizações de maior rigor no tratamento da violência doméstica. Neste aspecto, a Lei Maria da Penha é enunciada sempre como um grande avanço em relação aos tratamentos jurídicos anteriores. Contudo, mesmo mais rigorosa, a lei não sacia totalmente a sanha punitiva presente em algumas policiais, que questionam a possibilidade do pagamento de fiança nos casos de flagrantes e as penas previstas na condenação na esfera judicial. $O$ problema é ser afiançável, a própria mulher vem e solta o agressor, reclama um investigador. Você que pesquisa já viu algum homem ser preso pela Lei Maria da Penha?, indagou uma escrivã.

Ao mesmo tempo em que a Lei Maria da Penha pode ser "cavada" para conseguir puniçôes e tratamentos mais rigorosos, ela também pode ser "manipulada" no sentido inverso. As profissionais sabem que o enquadramento de fatos na normativa jurídica não é ingênuo ou simples. Elas argumentam que entre a norma, a realidade do trabalho policial e a complexidade das relaçôes sociais há muitos elementos que impedem uma adequação perfeita entre atos e autos. Muitas vezes, na polícia, a gente vê que, na prática, a lei é diferente daquilo que imaginamos na teoria. Não dá para ser exatamente igual na realidade, afirma uma delegada.

A possibilidade de utilizar a lei de diferentes maneiras é reconhecida pelas policiais. $\mathrm{Na}$ busca por lidar com o aumento significativo dos inquéritos trazido pela incondicionalidade da lesão corporal muitas profissionais admitem outras possibilidades de qualificaçâo, evitando a realização da investigação e do processo contra o acusado:

Se for um tapa, por exemplo, pode ser vias de fato, no qual devemos instaurar inquérito, ou injúria real, que precisa de representação. Aqui somos orientados a seguir com injúria real para evitar inquéritos, porque vias de fato é incondicionada (Escrivã).

A discussão acerca do que seria a figura da injúria real elucida alguns pontos importantes sobre práticas policiais e os vieses do direito. $\mathrm{Na}$ orientação para as escrivãs, algumas delegadas alegam que injúria real envolveria uma violência física que não deixasse marcas, como tapas e empurrôes. Outra maneira de registrar violência doméstica é a figura das vias de fato (art. $21 \mathrm{da}$ Lei de Contravençóes Penais), em geral envol- 
vendo agressóes mútuas que também não teriam deixado hematomas. Segundo as delegadas, lesóes necessitariam de comprovaçóes e indícios físicos do ocorrido, senão não terão valor como provas da violência. Por esse motivo, então, elas tenderiam a evitar registros de casos em que não haveria marcas como lesão corporal. Além disso, os casos de injúria real cairiam na rubrica da injúria e não se transformariam em inquéritos, o que ajudaria no cotidiano da delegacia.

A importância da materialidade da agressão para o seu enquadramento como lesão se evidencia nos laudos do IML enviados para a delegacia, que apenas descrevem marcas deixadas por agressóes nos corpos das vitimas, tais como "edemas", "escoriações" e "lesão lácero-contusa”. Laudos só confirmam violências quando estas se materializam em "ofensas à integridade física ou à saúde do examinado". ${ }^{15}$ A materialidade é uma questão central no direito, que opera com noçóes objetivadas de violência ${ }^{16} \mathrm{e}$ traz consequências importantes no tratamento dos casos entendidos como violência doméstica que transitam nas delegacias.

\section{O que dói mais? Algumas consideraçóes}

Busquei, neste artigo, delinear alguns elementos e questionamentos iniciais que têm aparecido em minha pesquisa de mestrado. Como se trata de um momento de organização e reflexão acerca de minha experiência de campo, trago resultados parciais, ainda em elaboração. Nesse sentido, é difícil apontar conclusôes e finalizações. Opto nesta seção, portanto, por indicar outras pistas que procuro seguir na tentativa da compreensão dos usos e significados da Lei Maria da Penha no contexto das delegacias especializadas, em especial a hierarquia na qual os casos atendidos são, muitas vezes, inseridos.
Nas delegacias, os casos de violência doméstica entendidos como lesôes são tratados como mais importantes e graves no que diz respeito à violência sofrida pelas vítimas. Já o crime de ameaça, por exemplo, gera opinióes divergentes entre as policiais justamente por ser compreendido como difícil de materializar nos corpos das mulheres. A figura da ameaça enquanto crime é demasiadamente ambígua no dia a dia das DDM. Se na percepção de algumas policiais seria comum que, em brigas, pessoas ameacem umas às outras sem que isso se transforme em ação - afinal, quem fala, não faz -, outras profissionais enfatizam justamente o inverso, ao afirmarem que a ameaça estaria mais próxima de um real risco à vida da vítima, uma vez que quem diz que vai matar, mata. Em ambos os casos, apesar de aparentemente contraditórios, confirma-se a importância de noçóes objetificadas de violência operacionalizadas pelo sistema jurídico, pois a gravidade de uma determinada situação parece ser avaliada de acordo com possíveis desfechos físicos para as vítimas.

Um caso de violência considerado extremamente grave de maneira mais generalizada entre as policiais seria uma tentativa de homicidio (art. 121 do Código Penal). Muitas policiais enfatizam a raridade dessas ocorrências nas delegacias especializadas. Podemos argumentar, entretanto, que sua raridade pode derivar do fato da polícia evitar registrar casos de violência doméstica sob esta rubrica. A decisão de registrar um ocorrido como tentativa de homicídio é extremamente polêmica e depende, sobretudo, da interpretação da delegada presente no plantâo. Eu aprendi que é tentativa de homicídio se for uma facada no peito. Estrangulamento pode ser só apertar o pescoço, daí registro como lesão. Nunca registrei tentativa de homicídio aqui, me explicou uma das delegadas.

Nas delegacias, os casos de assassinatos são percebidos como extremamente raros, quando 
não inexistentes. No entanto, isso talvez se deva mais à profunda desconexão entre os órgãos da Polícia Civil do quê à sua real ausência. Se uma mulher é assassinada em um contexto de violência doméstica, o crime deverá ser investigado pela divisão responsável por homicídios (DHPP) ou pelo distrito policial responsável pela área dos fatos. Mesmo que haja um inquérito ou uma ocorrência em uma das nove DDM da cidade, ou que a mulher até mesmo tenha medidas protetivas concedidas pela justiça, é muito improvável que tais informaçôes cheguem à delegacia especializada.

As profissionais da DDM não costumam tomar conhecimento do desfecho dos casos que por ali transitaram, seja do ponto de vista judicial - nas decisóes do Juizado -, seja suas consequências para as partes envolvidas. Em uma das delegacias, acompanhei o caso de uma mãe que avisou às policiais que sua filha havia sido morta pelo ex-namorado. A moça havia registrado ocorrência de ameaça e recebido medidas protetivas de urgência naquela delegacia, mas o desfecho trágico não foi evitado. Se a mãe não tivesse vindo aqui, nunca iríamos saber, me confessou consternada uma das escrivãs.

As injúrias, por sua vez, por serem entendidas como casos que não envolvem riscos físicos à integridade das vítimas, costumam ser tratadas como algo menos relevante pelas policiais. Não é só a polícia, contudo, que parece desmerecer os casos de ofensa, uma vez que na própria escala de nosso Código Penal, o crime de injúria ocupa lugar menos importante do que outros delitos.

Cardoso de Oliveira (2008), ao estudar a demanda por reparação a insultos nos tribunais de pequenas causas, chama atenção para o fenômeno do insulto moral, espécie de violência imaterial e emocional, ligada aos sentimentos, difícil de traduzir em termos jurídicos e que tende a ser tratada como menos importante e menos apta a ressarcimentos e puniçóes nas esferas jurídico-policiais. Para o autor, o direito positivo teria grande dificuldade em entender as dimensóes de indignação e ressentimento presentes nas vítimas de insultos, uma vez que esta agressão, embora fira a dignidade moral da vítima, não se explicita de forma material em corpos ou objetos.

Nas falas das mulheres que buscam os serviços das DDM torna-se evidente a insatisfação entre, de um lado, as vítimas e, de outro, as possibilidades dadas pelo direito e utilizadas pela polícia no tratamento dos insultos. Nos plantóes e nos depoimentos que acompanho, é comum que mulheres salientem o sofrimento causado pelas agressóes emocionais e ofensas morais que sofrem em âmbito doméstico como mais - ou tão - angustiantes e inaceitáveis quanto violências que se expressaram em seus corpos.

Nesse sentido, parece haver uma inversão entre a escala de prioridades do Código Penal brasileiro e os valores de algumas mulheres em situação de violência que apostam em uma saída jurídico-policial para seus problemas ao procurar pelas delegacias. Se, dentro da delegacia, a injúria é um crime menos importante, sendo necessário inclusive que um advogado entre com um processo diretamente na instância judiciária para o prosseguimento da acusação - e a lesão corporal aparece como um crime mais grave e automaticamente transformado em investigação -, para uma parte das mulheres que busca as DDM parece acontecer o oposto: seriam os insultos e as ofensas as faces mais nefastas e dolorosas da violência doméstica. Cicatrizes na alma são eternas, comentou uma vítima ao descrever sua relação conjugal. Nesse sentido:

A literatura antropológica ressalta que a noção popular de justiça não coincide necessariamente com a noção de Justiça definida pelos marcos legais. Esta parece distante e, muitas vezes, ininteligível às pessoas que recorrem a ela (BRAN- 
DÃO, 2006). Do mesmo modo, nem sempre a punição prevista para um determinado crime corresponde ao que os personagens envolvidos imaginam como castigo. Muitas vezes, espera-se um simples "corretivo" (MUNIZ, 1996) e não o desenrolar de um processo jurídico, cujos meandros raras vezes se tornam compreensíveis para os contendores (SARTI, 2012, p. 507).

\section{Notas}

1. Este artigo foi elaborado, incialmente, como apresentação oral para o III Encontro Nacional de Antropologia do Direito, realizado na Universidade de São Paulo, em agosto de 2013 e apresentado no GT 08 - Antropologia e Violência de Gênero. Parte deste artigo também foi apresentada e discutida no $10^{\circ}$ Fazendo Gênero, realizado em setembro de 2013, na Universidade Federal de Santa Catarina.

2. Acompanho todo o expediente policial realizado nas delegacias: desde o registro das denúncias, à colhida de depoimentos dos envolvidos, à conclusão policial dos casos e aos demais procedimentos jurídico-burocráticos efetuados pelas policiais. Por se tratar de resultados parciais, optei, neste momento da pesquisa, por não identificar as delegacias.

3. Optei por utilizar em itálico os termos mobilizados pelas policiais com quem interajo.

4. O estupro de vulnerável corresponde ao artigo 127-A do Código Penal, adicionado pela lei 12015, de agosto de 2009, que criminaliza como hediondo qualquer "conjunção carnal ou praticar outro ato libidinoso com menor de 14 (catorze) anos".

5. A lesão corporal pode ser leve ou grave, dependendo do entendimento da delegada do plantáo ou do resultado do exame de corpo-delito. Em geral, as escrivãs registram os inquéritos como LCD (lesão corporal dolosa) e aguardam os exames para tipificar a gravidade das lesóes.

6. Debert e Gregori (2008) chamam atenção para a necessidade de uma reflexão mais atenta sobre as diferentes formas de conceituar violências contra mulheres, compreendendo cada noção dentro de seus contextos e limites, e reconhecendo que estas não são intercambiáveis. Opto, neste artigo, por trabalhar com o conceito de "violência doméstica" não por considerar esta a melhor forma de conceitualização e classificação, mas por ser o termo utilizado no linguajar de minhas interlocutoras.

7. O Brasil ratificou dois tratados internacionais: a Convenção da ONU sobre Eliminação de todas as formas de discriminação contra a mulher (1984) e a Convenção Interamericana para prevenir, punir e erradicar a violência contra a mulher (1995).

8. Ver: Andrade (2012), Lemos (2010), OBSERVE/ UNIFEM (2011), Pasinato (2010), Zapater \& Perrone (2010), Santos (2008), Debert \& Gregori (2008) e Pasinato \& Santos (2008).

9. A expectativa é que o número continue a crescer em 2013. Até novembro deste ano, a segunda DDM estudada já contava com cerca de 2200 inquéritos policiais em seus cartórios.

10. A prática de utilizar a denúncia policial para "dar sustos" e/ou a subsequente "retirada da queixa" são questôes trabalhadas exaustivamente por pesquisadoras anteriores que investigaram a violência doméstica e as Delegacias de Defesa da Mulher. Brandão (2006), por exemplo, fornece a informação de que, apesar de ilegal, a prática de arquivamento de processos correspondia, antes da lei 9.099 , a mais de $70 \%$ dos casos atendidos nas delegacias especializadas, sendo a suspensão da queixa paradoxalmente censurada e favorecida pelas policiais. Tal prática também se tornou costumeira durante a vigência da lei 9.099, tanto nas delegacias quanto nos Juizados Especiais.

11. Há prazos curtos tanto para o envio dos inquéritos para os fóruns com as principais diligências (laudo do exame de corpo-delito e oitivas das partes) e para sua finalização (ou relato do inquérito). As delegadas-titulares e escrivãs-chefe são constantemente cobradas por órgãos superiores, da justiça e da polícia, para que inquéritos sejam relatados (finalizados, concluídos) em um curto espaço de tempo, o que gera apreensão e estresse constantes no trabalho.

12. É importante ressalvar que não é o mero registro do $\mathrm{BO}$ de lesão corporal e a instauração de um inquérito policial que implicam necessariamente na existência de uma ficha criminal para o acusado. Autores são planilhados ou indiciados, isto é, incluídos na base de dados daqueles com antecedentes criminais, por ordem de juízes ou em raras exceçốes em que as delegadas consideram tal medida aplicável, como alguns flagrantes.

13. Fala de uma escrivã à uma mulher que tinha dúvidas sobre realizar ou não a denúncia contra o ex-namorado.

14. Costuma-se falar também da criação de uma rede multidisciplinar de atendimento às mulheres em si- 
$300 \mid$ BeATriz ACCIOLY Lins

tuação de violência. No entanto, a articulação entre a delegacia e outros entes da rede de atendimento ainda é bastante precária. Em geral, apenas os abrigos estão em maior contato e mesmo assim há muita desinformação e decepção entre as partes envolvidas.

15. Estes termos são encontrados nos laudos de lesão corporal emitidos pelo Instituto Médico Legal.

16. Andrade (2012) e Sarti (2012).

\section{Referências bibliográficas}

ANDRADE, Fabiana de. Fios para trançar, jogos para armar: o fazer policial nos crimes de violência doméstica e familiar contra a mulher. Dissertação (Mestrado) Instituto de Filosofia e Ciências Sociais, Universidade de Campinas, São Paulo, 2012.

BERALDO DE OLIVEIRA, Marcella; DEBERT, Guita Grin. Os modelos conciliatórios de solução de conflitos e a violência doméstica. In: Cadernos Pagu, v. 29, p. 305-337, 2007.

BRANDÁO, Elaine Reis. Renunciantes de Direitos? A Problemática do Enfrentamento Público da Violência Contra a Mulher: o Caso da Delegacia da Mulher. In: Rev. Saúde Coletiva, v. 16, Rio de Janeiro, p. $207-$ 231, 2006.

CARDOSO DE OLIVEIRA, Luís Roberto. Existe Violência Sem Agressão Moral?. In: Revista Brasileira de Ciências Sociais. São Paulo, v. 23, p. 135-146, 2008.

DEBERT, Guita G.; GREGORI, Maria F. Violência e Gênero: novas propostas, velhos dilemas. In: Revista Brasileira de Ciências Sociais, v. 23, p. 165-185, 2008.

JUBB, Nadine (org) et al. Delegacias da Mulher na América Latina: uma porta para deter a violência e ter acesso à justiça. Quito: CEPLAES, 2010.

LEMOS, Marilda de Oliveira. Alivio e Tensão: um estudo sobre a interpretação e aplicação da Lei Maria da Penha nas Delegacias de Defesa da Mulher e Distritos Policiais da Seccional de Polícia de Santo André. Tese (Doutorado) Faculdade de Filosofia, Letras e Ciências Humanas, Universidade de São Paulo, São Paulo, 2010.

LIPSKY, Michael. Street level bureaucracy: dilemmas of the individual in public services. New York: The Russel Sage Foundation, 2010.

OBSERVE/UNIFEM. Identificando entraves na articulação dos serviços de atendimento às mulheres vitimas de violência doméstica e familiar em cinco capitais. Salvador: Observe, 2011. Disponível em: <www.observe. ufba.br>. Acesso em: 07 nov. 2013.

PASINATO, Wânia. Violência, gênero e acesso à justiça. In: JUBB, Nadine (org) et al. Delegacias da Mulher na América Latina: uma porta para deter a violência $e$ ter acesso à justiça. CEPLAES. Quito: CEPLAES, 2010. p. 165-199.

PASINATO, Wânia \& SANTOS, Cecília MacDowell. Mapeamento das Delegacias da Mulher no Brasil. Campinas: PAGU/UNICAMP, 2008.

SANTOS, Cecília MacDowell. Da Delegacia da Mulher à Lei Maria da Penha: Lutas feministas e políticas públicas sobre violência contra mulheres no Brasil. In: Oficina do CES, Centro de Estudos Sociais, n. 301. 2008. Disponível em: <http://rccs.revues.org/3759> Acesso em: 07 nov. 2013.

SARTI, Cynthia. Violência familiar: relaçôes violentas e contexto social. In: Lima, A. C.S. (coord.) Antropologia \& Direito - temas antropológicos para estudos juridicos. Rio de Janeiro: Nova Letra, 2012. p. 502-509.

ZAPATER, Maíra Cardoso \& PERRONE, Tatiana Santos. "A Lei Maria da Penha na prática: o cotidiano das Delegacias da Mulher de São Paulo". Disponível em: <http://www.fazendogenero.ufsc.br/9/resources/ anais/1278192683_ARQUIVO_OCotidianodasDDMemSP.pdf> Acesso em: 07 nov. 2013.

autora Beatriz Accioly Lins

Mestranda em Antropologia Social / USP

Recebido em 08/11/2013

Aceito para publicaşão em 16/12/201 